\title{
An improved harness for securing fecal collection bags to grazing cattle
}

\section{D.R. TOLLESON AND L.L. ERLINGER}

\section{Abatract}

An improved bovine fecal collection harness is described. The harness is durable, adjustable, and comfortable to the animal. The harneas has a wide variety of experimental applications.

\section{Key Words: fecal collection, sampling, measurements}

Measurement of fecal output of grazing cattle is often accomplished by fitting an animal with a fecal collection bag held in place by a harness (Garrigus and Rusk 1939). Modifications to the original concept have resulted in numerous designs for harnesses and fecal bags. Cammell (1977) described a double-girth harness using adjustable straps between the front and rear girths. The harness of Mitchell (1977) was constructed of an X-shaped, webbelt material and designed as an inexpensive collection apparatus for sheep. Other modifications include the addition of a urine collection bag for grazing cows and heifers (Lesperance and Boh-

Authors are research specialist and adjunct assistant professor with the Arkansas Agricultural Experiment Station, Fayetteville, Arkansas 72701.

This project was supported by the USDA, ARS through Cooperative Agreement number 58-7MN1-5-176.

Patent pending.

Manuscript accepted 9 March 1989. man 1961, Stillwell et al. 1983). In spite of the numerous designs available, the basic construction material has continued to be some type of rot-proof canvas webbing.

Workers at the South Central Family Farm Research Center (SCFFRC) in Booneville, Arkansas, have used the standard harness in forage intake and digestibility studies involving cattle with a wide range of frame scores (Erlinger and Tolleson 1988). However, this type of harness proved to be unsatisfactory under SCFFRC pasture and experimental conditions for several reasons. The entire weight of the fecal collection bag is supported by a $20.3 \times$ $25.4 \mathrm{~cm}(8 \times 10 \mathrm{in})$ canvas apparatus, therefore pressure on the animal is concentrated in a small area. The canvas apparatus frequently rips upon contact with fences and trees. Spring-steel snaps which open by downward pressure catch on corral panels as the animal moves about in confined quarters. Friction type buckles on the harness are difficult to adjust and the web-belt material of the straps often rubs and irritates the cattle. Feces is sometimes lost because of torn or improperly adjusted harnesses, and some cattle react adversely to the hamess and bag despite prior acclimation to 


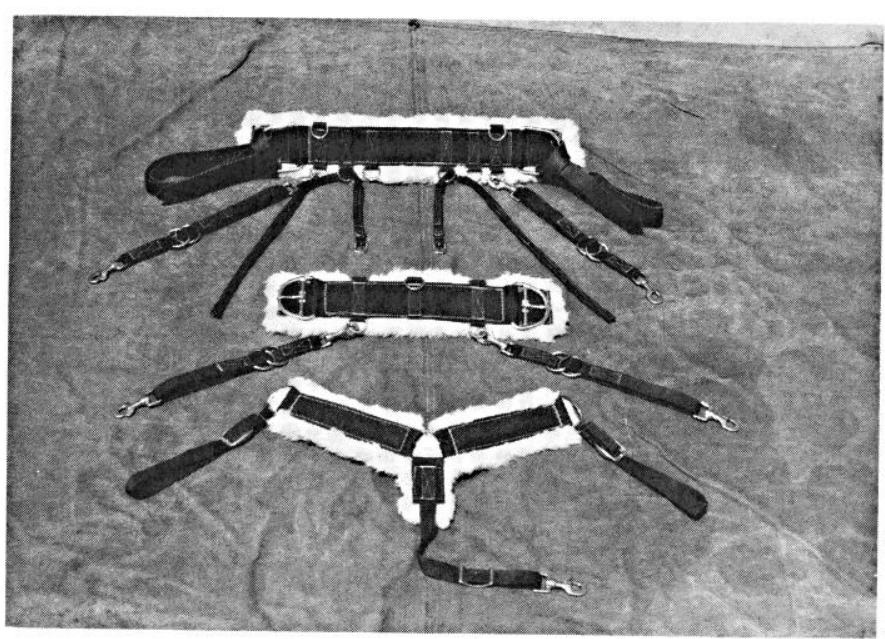

Fig. 1. The harness consists of (top to bottom): 1) Upper girth with latigos, top and side adjustable straps, 2) Lower girth with bottom adjustable straps, and 3) Breast collar with collar-to-upper-girth straps and the brisket strap.

a "practice" harness. Because of these problems, a harness that is more durable in pasture situations, easily adjusts to different sizes of cattle, and perhaps most importantly, is more comfortable to the animals themselves, was developed.

\section{Materials and Methods}

Materials used in the construction of the harness include nylon straps, leather latigo straps, synthetic fleece, and stainless steel hardware. Figure 1 illustrates the component parts of the harness, and Figure 2 diagrams the placement of each component on the animal including attachment of the fecal collection bag. The harness consists of an upper and lower girth, latigos to connect the girths, a breast collar, and 3 pair of adjustable straps (top, side, and bottom) that connect to the fecal collection bag. Specifications of each component for various size animals are given in Table 1.

The upper girth (Fig. 1) is a $7.6 \mathrm{~cm}$ ( 3 in) wide, fleece-lined nylon strap. There is a $7.6 \mathrm{~cm}(3 \mathrm{in}) \mathrm{D}$ ring at each end of the girth. Leather latigo straps $162.5 \mathrm{~cm}$ long $\times 3.8 \mathrm{~cm}$ wide $(64 \times 11 / 2 \mathrm{in})$ are attached to each large $D$ ring. There are 8 small, $2.54 \mathrm{~cm}$ ( 1 in) D rings, 6 pointing toward the rear of the animal and 2 pointing forward. The adjustable straps attach to the posterior $D$ rings, and the breast collar attaches to the anterior D rings. Most of the weight of the collection bag is borne by the upper girth. Therefore, the upper girth is designed to distribute weight over a large area and is more comfortable to the animal than was the previous model.

The lower girth (Fig. 1) is similar to the upper one except it has a $7.6 \mathrm{~cm}(3 \mathrm{in})$ double-bar cinch buckle on each end and contains only 3 small $\mathrm{D}$ rings. One $\mathrm{D}$ ring points forward for attachment to the breast collar strap that lies between the animal's front legs; the 2 $D$ rings face toward the rear to connect to the adjustable straps which lie along the ventral side of the animal between the rear legs to the collection bag. The upper and lower girths are pulled securely around the animal by the latigo straps. In contrast to the web-belt material, the padding in the girths offers protection against chafing during the normal movement of the animal.

The breast collar (Fig. 1) is constructed of $5.1 \mathrm{~cm}(2$ in) or $7.6 \mathrm{~cm}$ ( 3 in) wide for larger animals, fleece-lined nylon straps. A D ring of corresponding size is located at each end of the breast collar and in the center of the collar where the $10 \mathrm{~cm}$ (4 in) long drop strap is located. The breast collar is positioned under the animal's neck (Fig. 2) and attaches to the upper girth on both sides with $2.54 \mathrm{~cm}$ ( 1 in) nylon straps adjustable through the use of $2.54 \mathrm{~cm}$ (1 in) double-bar buckles. In the center of the breast collar is a $50.8 \mathrm{~cm}$ long $\times 2.54 \mathrm{~cm}(20 \times 1$ in $)$ adjustable strap which lies between the animal's front legs and attaches to the center D ring on the lower girth by means of a $2.54 \mathrm{~cm}(1 \mathrm{in})$ trigger snap. The breast collar keeps the entire harness, and thus the collection bag, in the proper position.

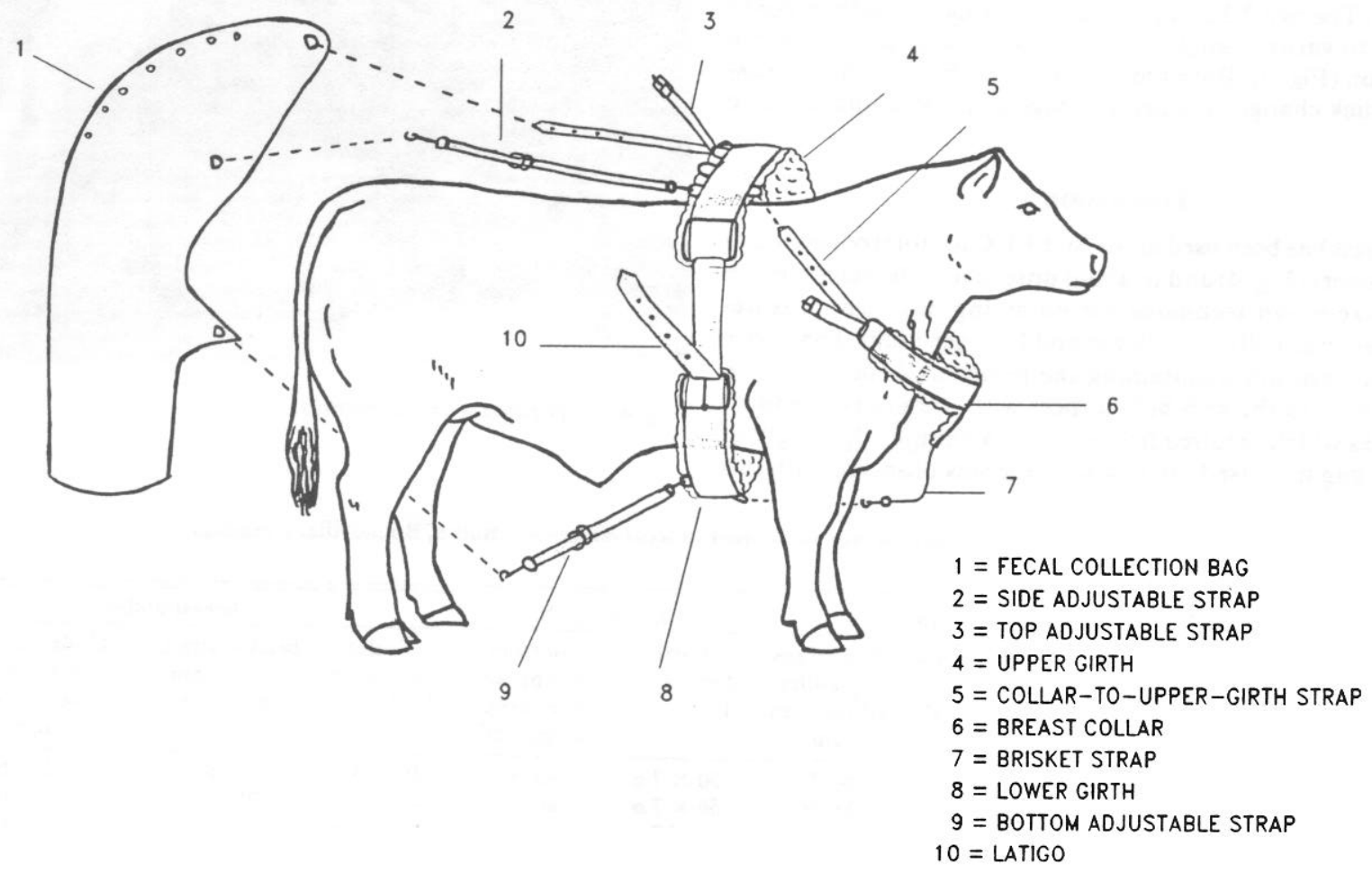

Fig. 2. Identification and placement of each harness component on the experimental animal. 


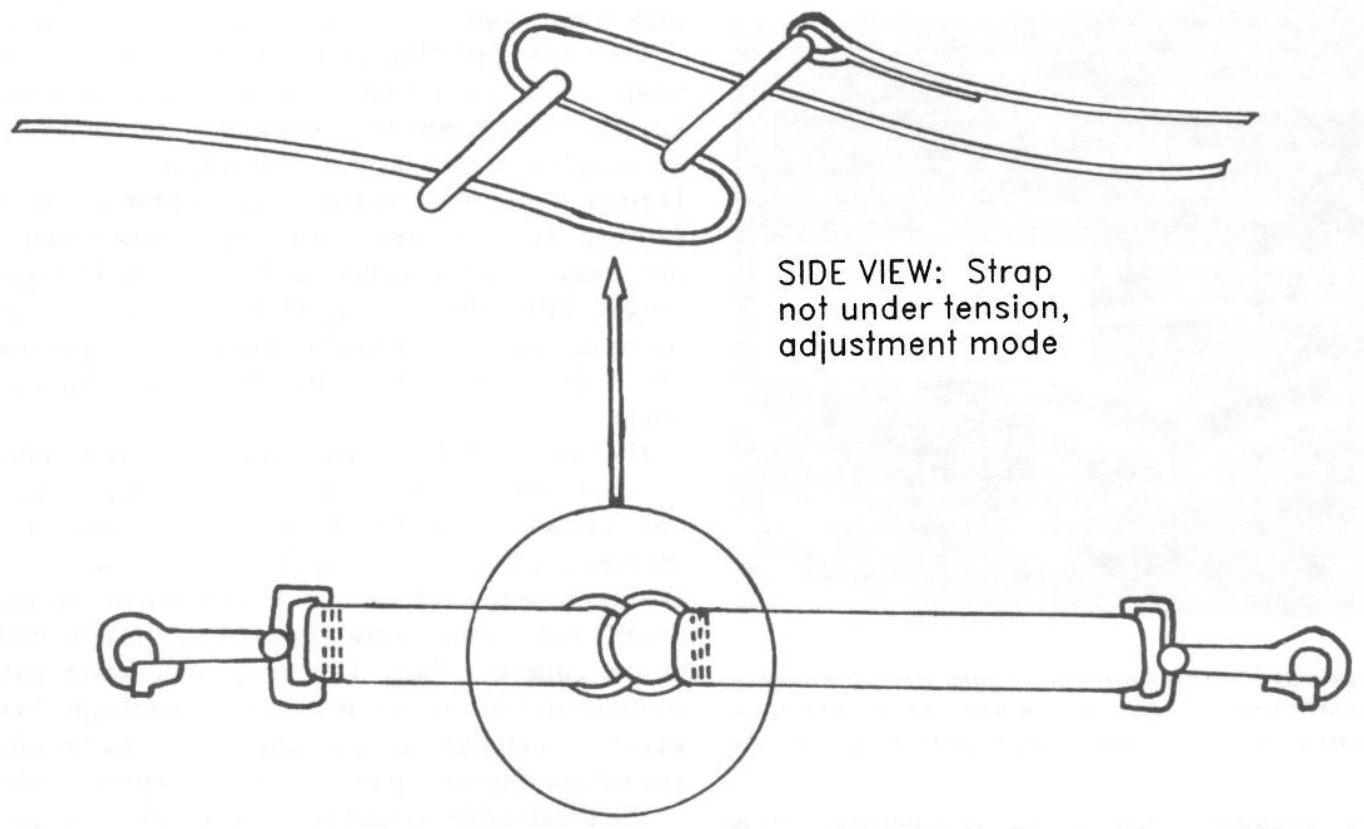

TOP VIEW: Strap under tension

Fig. 3. Side and bottom adjustable girth strap demonstrating the principle of the non-slip adjustment rings.

Two types of nylon straps are used to connect the harness to the fecal collection bag. The top adjustable straps on the upper girth (Fig. 1) are similar to a dog collar. Constructed of $1.6 \mathrm{~cm}$ (5/8 in) nylon and a corresponding size double-bar buckle, these straps are placed through the small $\mathrm{D}$ rings on the harness and the collection bag and then buckled to proper length. The other type strap (Fig. 3) connects the collection bag to the sides and bottom of the harness. This is a $2.54 \mathrm{~cm}$ ( 1 in) double strap with $2.54 \mathrm{~cm}$ ( 1 in) trigger snaps on each end. The two $3.2 \mathrm{~cm}(11 / 4$ in) metal rings allow the strap to be adjusted to various lengths (Table 1) as long as the strap is not under tension (Fig. 3). Both types of straps utilized in this harness allow for quick change of collection bags and easy adjustments in the field.

\section{Discussion}

This harness has been used at the SCFFRC for total collection of feces from steers (Fig. 4) and to avoid unrecoverable weight loss in a weigh-graze-weigh technique for obtaining bite size measurements on pastured heifers (Tolleson and Erlinger 1989). The device does an excellent job maintaining the position of the collection bag. Compared to the web-belt harness with friction type adjustment buckles which required frequent retightening as the weight of

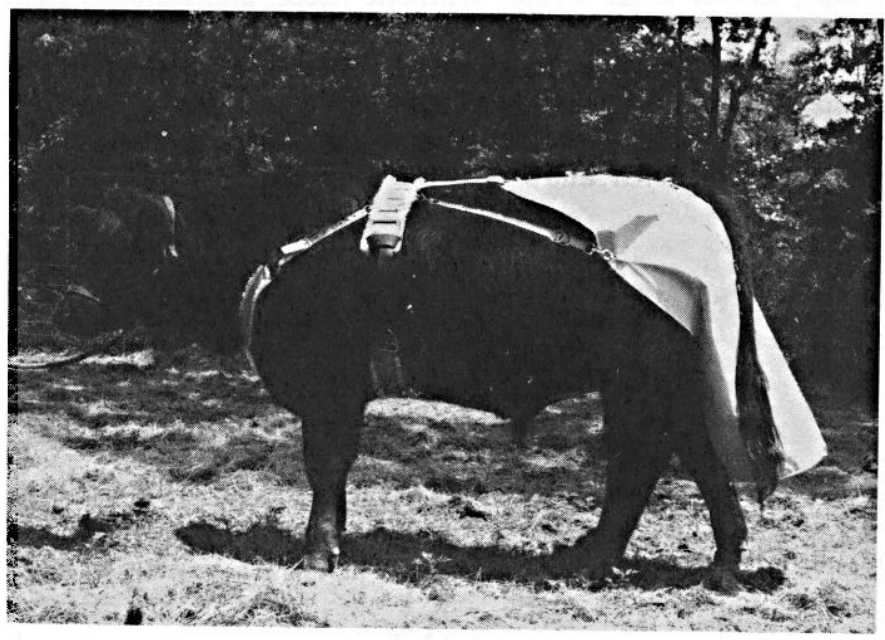

Fig. 4. Steer fitted with the harness. feces in the bag increased, no bag slippage was observed with this

Table 1. Specifications of harness components for various size cattle used in fecal collection studies, Booneville, Arkansas.

\begin{tabular}{|c|c|c|c|c|c|c|c|c|c|}
\hline \multicolumn{2}{|c|}{ Animal size } & \multicolumn{3}{|c|}{ Upper girth } & \multicolumn{2}{|c|}{ Lower girth } & \multicolumn{3}{|c|}{ Breast collar } \\
\hline $\begin{array}{l}\text { Weight, } \\
\text { kg }\end{array}$ & $\begin{array}{l}\text { Hip } \\
\text { height, } \\
\mathrm{cm}\end{array}$ & $\begin{array}{c}\text { Girth } \\
\text { dimensions } \\
\text { LXW, cm }\end{array}$ & $\begin{array}{c}\text { Side straps } \\
\text { adjustment } \\
\text { range } \mathrm{cm}^{\mathrm{a}}\end{array}$ & $\begin{array}{c}\text { Top straps } \\
\text { (dog collar), } \\
\text { adjustment } \\
\mathrm{cm}\end{array}$ & $\begin{array}{c}\text { Girth } \\
\text { dimensions } \\
\text { LXW, cm }\end{array}$ & $\begin{array}{c}\text { Bottom } \\
\text { straps, ad- } \\
\text { ment range, } \\
\text { range, } \mathrm{cm}^{\mathrm{a}, \mathrm{b}}\end{array}$ & $\begin{array}{c}\text { Collar } \\
\text { dimensions } \\
\text { LXW, } \mathrm{cm}^{\mathrm{c}}\end{array}$ & $\begin{array}{l}\text { Brisket strap, } \\
\text { adjustment } \\
\text { range, } \mathrm{cm}\end{array}$ & $\begin{array}{l}\text { Collar-to-upper } \\
\text { girth straps, } \\
\text { adjustment } \\
\text { range, cm }\end{array}$ \\
\hline $\begin{array}{l}170-270 \\
230-330 \\
330-430\end{array}$ & $\begin{array}{r}95-110 \\
110-125 \\
125-135\end{array}$ & $\begin{array}{l}60 \times 7.6 \\
60 \times 7.6 \\
60 \times 7.6\end{array}$ & $\begin{array}{l}46-66 \\
46-66 \\
60-95\end{array}$ & $\begin{array}{l}20-30 \\
25-30 \\
30-50\end{array}$ & $\begin{array}{l}50 \times 7.6 \\
56 \times 7.6 \\
62 \times 7.6\end{array}$ & $\begin{array}{l}40-56 \\
40-62 \\
56-86\end{array}$ & $\begin{array}{l}50 \times 5.1 \\
66 \times 5.1 \\
80 \times 7.6\end{array}$ & $\begin{array}{l}25-40 \\
25-40 \\
25-40\end{array}$ & $\begin{array}{l}15-25 \\
20-30 \\
20-30\end{array}$ \\
\hline
\end{tabular}

${ }^{a}$ Adjustment range includes snap on each end.

${ }^{\text {b }}$ For extremely long-body cattle in the $330-430 \mathrm{~kg}$ weight range a strap adjustable to $115 \mathrm{~cm}$ is required.

${ }^{\mathrm{c}}$ Breast collar has a $10 \mathrm{~cm}$ drop on center $\mathrm{D}$ ring for attachment of brisket strap. 
harness when the bags were emptied twice daily. The bag can actually be secured so tightly that defecation will become difficult, and the animal will be observed straining as if constipated. Caution must therefore be taken not to adjust the harness too tightly. The harness needs to be secure enough only to prevent slippage; i.e., the girth need not be as tight as that on a saddle. When the harness is properly adjusted, animal comfort appears to be quite satisfactory.

The nylon material is available in several colors which can aid identification of grazing animals in large pastures. The materials can be obtained from and constructed by shops involved in manufacturing tack for the equine industry. Cost of the harness is reasonable. A conventional harness complete with collection bag has been selling for $\$ 80-90$ per set with itemized costs being equally divided between the harness and bag when purchased separately. Cost of the harness described herein was approximately $\$ 10$ higher than that of the conventional harness.

Maintenance is relatively easy. Cleanup between collection periods can be accomplished with a water hose. Both the nylon and fleece materials are machine washable, and a thorough cleaning in this manner is recommended prior to storage of the harness between experiments. The leather latigos should be conditioned with an appropriate oil.
In summary, this harness is durable, adjustable, comfortable to the animal and can be adapted to a wide variety of experimental applications. The harness should be compatible with any of the commonly used fecal collection bags.

\section{Literature Cited}

Cammel], S.B. 1977. Equipment and techniques used for research into the intake and digestion of forages by sheep and calves. Grassland Research Institute Tech. Rep. 24. pp 37-40.

Erlinger, L.L., and D.R. Tolleson. 1988. Factors associated with grazing behavior in cattle: The effects of frame size and rate of maturity. J. Anim. Sci. (Suppl. 1) 66:50 (Abstr.).

Garrigus, W.P., and H.P. Rusk. 1939. Some effects of the species and stage of maturity of plants on the forage consumption of grazing steers of various weights. Ill. Agr. Exp. Sta. Bull. 454.

Lesprance, A.L., and V.R. Bohman. 1961. Apparatus for collecting exereta from graxing cattle. J. Anim. Sci. 20:503-505.

Mitchell, A.R. 1977. An inexpensive metabolic harness for female sheep. British Vet. J. 133:483-485.

Stillwell, M.A., R. Semft, and L.R. Rittenhouse. 1983. Total urine collection from free-grazing heifers. J. Range Manage. 36:798-799.

Tolleson, D.R., and L.L. Erlinger. 1989. Effects of bite size and biting rate measurements on estimated intake of grazing heifers. J. Anim. Sci. (Suppl. 1) 67:50 (Abstr.).

\title{
We've waited for it. Now it's here:
}

\section{The Glossary of terms used in range management.}

\author{
Available for $\$ 5.00$ (US) per copy from the Society for Range Management, 1839 York \\ Street, Denver, CO 80206. Telephone: (303)355-7070.
}

